\title{
Exigência de energia de mantença e composição corporal e do ganho de vacas de corte adultas de três grupos genéticos confinadas ${ }^{1}$
}

\author{
João Gomes de Siqueira ${ }^{2}$, Carlos Augusto de Alencar Fontes ${ }^{3}$, Alexandre Leite Pereira ${ }^{4}$, \\ Cláudio Teixeiras Lombardi ${ }^{4}$, Nivaldo de Faria Sant ${ }^{\prime} \mathrm{Ana}^{5}$, Ricardo Augusto Mendonça Vieira ${ }^{3}$
}

1 Projeto parcialmente financiado pelo CNPq.

2 Doutor em Produção Animal.

${ }^{3}$ LZNA/CCTA/UENF. Bolsista do CNPq

${ }^{4}$ Mestre em Produção Animal.

${ }^{5}$ Doutorando em Produção Animal (LZNA/CCTA/UENF).

RESUMO - Neste trabalho, foram estimadas as exigências de mantença de energia líquida (ELm) e metabolizável $(E M m)$ e as mudanças na composição corporal e no ganho de vacas adultas não-gestantes e não-lactantes confinadas Foram utilizadas 36 vacas, 12 Nelore (NEL), 12 F1 Pardo-Suíço-Nelore (PSN) e 12 F1 Red Angus-Nelore (RAN). As alterações na composição corporal dos animais durante o período experimental foram estimadas utilizando-se a técnica do abate comparativo: quatro animais de cada grupo genético foram alocados, aleatoriamente, nos tratamentos abate inicial (AI), alimentação restrita (AR) e alimentação ad libitum (AL). Os animais AR receberam, no período experimental, níveis de proteína e energia $15 \%$ acima da mantença e os $\mathrm{AL}$, ração ad libitum, para ganho de $1,1 \mathrm{~kg} / \mathrm{dia}$. Os animais $\mathrm{AI}$ foram abatidos no início do experimento e os AR e AL 120 dias depois. Em todos os animais abatidos, foram estimadas as proporções corporais dos tecidos muscular, adiposo e ósseo, além dos conteúdos corporais de proteína, gordura e energia. Na estimação da ELm e da EMm, foram empregados modelos linear e não-linear. Os grupos genéticos não diferiram quanto às exigências de ELm e EMm, expressas em peso vivo em jejum ( $\mathrm{kcal} / \mathrm{kg} 0,75 / \mathrm{dia}$ PVJ). Quando utilizados os modelos linear e não-linear, os valores de ELm encontrados foram de 80,7 e $83,6 \mathrm{kcal} / \mathrm{kg}^{0,75} / \mathrm{dia}$ PVJ e os de EMm, 109,9 e $128,0 \mathrm{kcal} / \mathrm{kg}^{0,75} / \mathrm{dia} \mathrm{PVJ}$, respectivamente. Os conteúdos de proteína por unidade de peso corpo vazio (PCVZ) e do ganho (GPCVZ) não diferiram entre os grupos genéticos, porém, os animais NEL apresentaram maior concentração de gordura e energia por kg PCVZ e GPVCZ para mesmo peso vivo.

Palavras-chave: energia líquida, energia metabolizável, Nelore, Pardo-Suíço, Red Angus

\section{Maintenance energy requirements and body and gain composition of adults beef cows from three genetic groups}

\begin{abstract}
This research aimed to estimate the maintenance requirements of net energy (NEm) and metabolizable energy (MEm), and the changes in body and gain composition of confined adults non-pregnant and nonlactant beef cows. Thirty six cows were used, 12 were Nellore (NEL), 12 F1 Brown Swiss-Nellore (BSN) and 12 F1 Red Angus-Nellore (RAN). The comparative slaughter method was utilized to estimate the changes of animal body chemical composition during the experimental period. Four animals from each breed group were randomly allocated to the treatments: initial slaughter (IS), restrict feeding (RF) and ad libitum feeding (AL). The RF animals received levels of energy and protein $15 \%$ above maintenance during the experimental period, while the AL group was fed ad libitum, to gain $1.1 \mathrm{~kg}$ liveweight (LW) daily. The IS animals were slaughtered at the beginning of the experimental period, and those from RF and AL treatments were slaughtered 120 days latter. The proportions of muscle, adipose tissue and bone beyond body content of protein, fat and energy were estimated in all slaughtered animals. Linear and non linear models were fitted to estimate the NEm and MEm requirements. There was no difference among breed groups for NEm and MEm requirements expressed fast body weight ( $\left.\mathrm{kcal} / \mathrm{kg}^{0.75} \mathrm{FBW}\right)$. When the linear and the non linear models were fitted, it was observed values of NEm requirements of 80.7 and $83.6 \mathrm{kcal} / \mathrm{kg}^{0.75} \mathrm{FBW}$, and the MEm requirements of 109.9 and $128.0 \mathrm{kcal} / \mathrm{kg}^{0.75} \mathrm{FBW}$, respectively. Breed groups did not differ with respect to protein content per unit of empty body weight (EBW) and of empty body weight gain (EBG). However, NEL animals showed higher fat and energy concentrations per $\mathrm{kg} \mathrm{EBW}$ and $\mathrm{EBG}$, at a given live weight.
\end{abstract}

Key Words: Brown Swiss, metabolizable energy, Nellore, net energy, Red Angus 


\section{Introdução}

Os programas de cruzamento envolvendo raças européias e zebuínas visam obter, em curto prazo, animais que conciliem da melhor forma a adaptação ao meio, o potencial produtivo e alta qualidade de carcaça. O estudo das características de produção das raças existentes e a avaliação dos produtos mestiços são etapas fundamentais que devem anteceder o estabelecimento dos sistemas de cruzamento, de forma a proporcionar maior eficiência na produção de gado de corte (Long, 1980).

No Brasil, os estudos direcionados a aspectos funcionais de animais de raças zebuínas e seus mestiços receberam maior ênfase em anos mais recentes. No entanto, as pesquisas sobre exigências nutricionais têm enfocado, basicamente, animais em fase de crescimento/engorda (Berndt et al., 2004; Boin, 1995; Fontes, 1995; Paulino et al., 2004), gerando grande carência de informações relacionadas às exigências nutricionais de vacas zebuínas ou mestiças.

As exigências de mantença das vacas representam parte expressiva da energia alimentar necessária à produção de carne. Da energia total consumida por uma vaca de corte, ao longo do ano, incluindo-se as exigências para gestação e lactação, cerca de $70 \%$ destinam-se a atender às exigências de mantença. Considerando o sistema produtivo como um todo, $50 \%$ da energia total requerida para produção de novilhos de corte destina-se à mantença das vacas (Ferrell \& Jenkins, 1984, 1985).

A exigência energética de animais em mantença tem sido determinada por diferentes métodos: experimentos de longa duração, nos quais o peso ou o nível de alimentação dos animais é mantido fixo; ensaios calorimétricos e abate comparativo (Lofgreen \& Garrett, 1968; ARC, 1980; NRC, 2000). Todas essas técnicas possuem vantagens e desvantagens (NRC, 2000), no entanto, o abate comparativo é o mais amplamente utilizado para bovinos de corte tem possibilitado resultados que constituem a base do Sistema Californiano de Energia Líquida, origem do atual sistema de alimentação americano para gado de corte (Lofgreen \& Garrett, 1968; NRC, 2000).

A exigência energética pode variar entre grupos genéticos. Diferenças genéticas podem ocasionar variação de 20 a 30\% nas exigências de energia de mantença, característica de herdabilidade de moderada a alta (Taylor \& Young, 1968). Neste sentido, O NRC (2000) estabeleceu que bovinos Bos indicus em crescimento requerem $10 \%$ menos energia para mantença que os Bos taurus de raças de corte. Os mestiços apresentam valores inter- mediários. Maiores exigências teriam animais Bos taurus de raças de leite ou de duplo propósito (Ayrshire, PardoSuíço, Holandês e Simental), que requerem $20 \%$ mais energia que as raças de corte, enquanto os mestiços teriam exigências intermediárias.

Admite-se que, a um mesmo grau de maturidade, a composição corporal dos bovinos é igual (Owens et al., 1993; NRC, 2000). No entanto, animais de portes distintos atingem o mesmo grau de maturidade em diferentes pesos corporais. Desse modo, em mesmo peso corporal, raças mais precoces, de menor porte, apresentam mais gordura e menos proteína na composição do ganho e no corpo em comparação a raças menos precoces, de maior porte (ARC, 1980; NRC, 2000).

Este trabalho foi realizado para estimar as exigências de energia de mantença e as mudanças da composição corporal e do ganho de vacas Nelore e mestiças Europeu-Nelore em confinamento.

\section{Material e Métodos}

A pesquisa foi realizada em dependências do Laboratório de Zootecnia e Nutrição Animal (LZNA) da Universidade Estadual do Norte Fluminense - UENF, em Campos dos Goytacazes, RJ. O período experimental teve duração de 120 dias e foi realizado no período de agosto e dezembro de 2002 .

Foram utilizadas 36 vacas adultas, não-gestantes e nãolactantes, com condição corporal moderada ( 4 em uma escala de 1 a 9), 12 Nelore, 12 F1 Pardo-Suíço-Nelore e 12 F1 Red Angus-Nelore, adquiridas em criatórios da região Norte Fluminense. As vacas foram mantidas confinadas em baias individuais, com área de $12 \mathrm{~m}^{2}$, com $6 \mathrm{~m}^{2}$ cobertos com telhas de amianto, providas de comedouro de concreto e bebedouro.

Durante o período de adaptação, que durou 45 dias, as vacas foram submetidas ao controle de endo e ectoparasitos, identificadas com brincos numerados e receberam 2.000.000 UI de vitamina $\mathrm{A}$, sendo vacinadas contra febre aftosa. $\mathrm{Na}$ adaptação, todas as vacas receberam, individualmente, a mesma ração utilizada no período experimental, em quantidade suficiente para suprir nível de energia $30 \%$ acima das necessidades individuais de mantença.

A ração foi constituída de $37,5 \%$ de concentrado e $62,5 \%$ de volumoso, na MS (Tabela 1). O volumoso foi composto da mistura das silagens de sorgo (Sorghum bicolor) e de capim-elefante (Pennisetum purpureum), na proporção de $50 \%$ cada um. O concentrado foi constituído de milho $(85,0 \%)$, farelo de soja $(9,7 \%)$, uréia $(2,4 \%)$ e suplemento mineral comercial $(2,9 \%)$. 
Tabela 1 - Composição química e energética da ração completa (\% MS)

Table 1 - Chemical and energy composition of the complete diet (\% DM)

\begin{tabular}{|c|c|c|c|c|c|c|c|}
\hline \multirow[b]{2}{*}{ MS } & \multirow[b]{2}{*}{ MO } & \multicolumn{5}{|c|}{$\begin{array}{c}\text { Porcentagem na MS } \\
\text { Percentage in the } D M\end{array}$} & \multirow[b]{2}{*}{$\mathrm{EM}^{1}$} \\
\hline & & $\mathrm{PB}$ & FDN & $\mathrm{CNF}$ & $\mathrm{MM}$ & $\mathrm{EE}$ & \\
\hline 43,8 & 93,8 & 10,9 & 54,0 & 26,1 & 6,2 & 2,7 & 2,4 \\
\hline
\end{tabular}

${ }^{1}$ Determinado por meio de ensaio de digestibilidade, considerando $\mathrm{EM}=\mathrm{ED} \times 0,82$.

${ }^{1}$ Determined in digestibility assay, admitting that $M E=D E \times 0.82$

As mudanças na composição química corporal dos animais durante o período experimental foram estimadas utilizando-se a técnica do abate comparativo (Lofgreen \& Garrett, 1968): os animais de cada grupo genético foram distribuídos de acordo com o peso vivo e a condição corporal, em três lotes semelhantes, alocados aleatoriamente nos tratamentos abate inicial (AI), alimentação restrita (AR) e alimentação ad libitum (AL).

As vacas do tratamento AI foram abatidas ao final do período de adaptação e serviram como referência no estudo da composição corporal inicial dos animais. Os animais do tratamento AL receberam ração ad libitum, formulada segundo as normas do NRC (2000) para ganho diário de $1,1 \mathrm{~kg}$. A quantidade de ração fornecida foi ajustada de forma que as sobras se mantivessem entre 5 e $10 \%$ do ofertado. Os animais do lote AR receberam a mesma ração, em quantidades limitadas, de forma a ingerirem energia e proteína em quantidades $15 \%$ acima das exigências de mantença (NRC, 2000). Para todos os animais, a ração foi fornecida uma vez ao dia.

No fim do período experimental, os animais dos tratamentos AR e AL foram abatidos. Após o abate, foram pesados todos os componentes corporais e coletadas, processadas e analisadas amostras representativas de órgãos e tecidos corporais visando determinar os conteúdos corporais de gordura, proteína, água e cinzas de cada vaca. Os procedimentos adotados seguiram a metodologia descrita por Fontes et al. (2005).

O conteúdo corporal de energia foi estimado a partir dos conteúdos corporais de proteína e gordura e de seus respectivos equivalentes calóricos, conforme equação proposta pelo ARC (1980):

$$
\mathrm{CE}(\mathrm{mcal})=5,6405 \mathrm{X}+9,3929 \mathrm{Y} \text {, }
$$

em que $\mathrm{CE}=$ conteúdo corporal de energia; $\mathrm{X}=$ proteína corporal $(\mathrm{kg}) ; \mathrm{Y}=$ gordura corporal $(\mathrm{kg})$.

A ração fornecida e as sobras de cada animal foram pesadas e amostradas diariamente. As amostras foram acondicionadas em sacos plásticos e congeladas a $-20^{\circ} \mathrm{C}$. Posteriormente, as amostras diárias individuais de ração e sobras foram agrupadas, proporcionalmente, em amostras compostas correspondentes aos períodos sucessivos de 28 dias. As amostras compostas foram pré-secas em estufa de ventilação forçada, à temperatura de $55 \mathrm{a} 60^{\circ} \mathrm{C}$, durante 72 horas. Em seguida, foram moídas em moinho de facas com peneira de crivos de $2 \mathrm{~mm}$ e analisadas para determinação dos teores de energia bruta (EB), PB, FDN e cinzas, segundo metodologia descrita por Silva \& Queiroz (2002).

Os coeficientes de digestibilidade aparente da EB foram determinados em ensaio de digestibilidade utilizando-se o FDNi como indicador interno. Durante nove dias, foram coletadas as fezes de três animais de cada tratamento, escolhidos previamente ao acaso, às 8 e às $16 \mathrm{~h}$. As amostras de fezes foram acondicionadas em sacos plásticos e armazenadas em congelador a $-20^{\circ} \mathrm{C}$. Posteriormente, depois de pré-secas e moídas, as amostras individuais da ração fornecida, das sobras e das fezes de cada animal foram agrupadas proporcionalmente em amostras compostas, correspondentes aos nove dias do ensaio de digestibilidade. Os conteúdos de EB das amostras compostas de fezes, ração fornecida e sobras foram determinados em bomba calorimétrica, segundo técnica descrita por Silva \& Queiroz (2002).

A estimação dos teores de FDNi, referentes ao ensaio de digestibilidade, nas amostras compostas de fezes, da ração fornecida e das sobras foi realizada pelo procedimento in situ, em adaptação ao protocolo descrito por Lippke et al. (1986). As amostras foram acondicionadas em sacos de náilon com porosidade de $50 \mu \mathrm{m}$, na proporção de $15 \mathrm{mg}$ de amostra por $\mathrm{cm}^{2}$ de superfície (Nocek, 1988), os quais foram selados na borda por fusão com resistência elétrica e incubados no rúmen de um bovino alimentado com dieta mista de $66 \%$ de volumoso e $34 \%$ de concentrado por 144 horas. Após esse período, os sacos foram retirados, lavados em água corrente e submetidos a tratamento em detergente neutro (Goering \& Van Soest, 1970), na proporção de $50 \mathrm{~mL} /$ saco, lavados com água quente e acetona e secos em estufa de ventilação forçada $\left(65^{\circ} \mathrm{C}-72\right.$ horas $)$. Em seguida, foram secos em estufa a $105^{\circ} \mathrm{C}$ por 1 hora, acondicionados em 
dessecador e pesados. Os sacos foram previamente tarados após procedimento de secagem semelhante.

O conteúdo de energia metabolizável (EM) da ração foi estimado utilizando-se o fator 0,82 na conversão de ED em EM (NRC, 2000). A partir do conteúdo de EM da ração e do consumo de cada animal, foi calculado o consumo de energia metabolizável (CEM) individual de todas as vacas.

A retenção diária de energia foi expressa por unidade de tamanho metabólico (UTM), tanto em peso vivo em jejum ( $\mathrm{kg}^{0,75} \mathrm{PVJ}$ ) quanto em peso corporal vazio ( $\mathrm{kg}^{0,75} \mathrm{PCVZ}$ ). A diferença entre o $\mathrm{CEM}$ e $\mathrm{a}$ ER equivale à produção de calor (PC) do animal (Lofgreen \& Garrett 1968).

A energia retida (ER) no corpo dos animais dos tratamentos AR e AL foi obtida subtraindo-se do conteúdo corporal final de energia, determinado após o abate de cada animal. O conteúdo inicial estimado de energia, por sua vez, foi calculado com base no PVJ inicial do animal e na relação $\mathrm{PVJ} / \mathrm{PCVZ}$ e na composição corporal observada nos animais AI (abatidos no início do experimento), pertencentes ao mesmo grupo genético.

As exigências de energia líquida para mantença (ELm) de cada grupo genético foram determinadas pela regressão do logaritmo da PC de acordo com o consumo de energia metabolizável (CEM), em kcal/UTM/dia, utilizando-se o PCVZ e o PVJ no cálculo do tamanho metabólico e extrapolando-se a equação para o nível zero de CEM (Lofgreen \& Garrett, 1968). As comparações entre grupos genéticos foram feitas utilizando-se teste de identidade de modelos (Graybill, 1976).

Alternativamente, a ELm foi estimada utilizando-se diretamente o modelo não-linear abaixo, proposto pelo NRC (1981), sem transformação logarítmica, de forma a se verificar a equivalência dos resultados obtidos.

$$
\operatorname{PCi}(\mathrm{UTM})=\alpha \cdot \exp (\beta . \mathrm{CEMi})+\mathrm{ei},
$$

em que $\alpha$ é o parâmetro para se estimar a produção de calor em jejum e $\beta$, à ELm.

A exigência de energia metabolizável de mantença $(\mathrm{EMm})$ foi estimada igualando-se a zero a equação obtida por meio da regressão da ER sobre o CEM (NRC, 2000). Alternativamente, a EMm foi estimada com base no modelo não-linear proposto pelo NRC (1981), no qual foram substituídos os parâmetros por suas estimativas, e calculado numericamente pela operação do modelo até que o quociente PCi (UTM) /CEMi fosse aproximadamente 1,000. Então, a exigência em ER (ganho) foi estimada utilizando-se o modelo linear restrito (NRC, 1981):

$\mathrm{ERi}=\gamma+\delta . \mathrm{CEMi}+$ ei sujeito à restrição: $\gamma+\delta . \mathrm{EMm}=0$ (Henrique et al., 2005),

no qual $\gamma$ é o intercepto e equivale a $-\alpha . \mathrm{kg} / \mathrm{Km}$ e $\delta$, a eficiência líquida de ganho, $\mathrm{kg}$.
A eficiência de utilização da energia metabolizável da ração para a mantença $(\mathrm{Km})$ foi determinada como o quociente da fração $\mathrm{Km}=\mathrm{ELm} / \mathrm{EMm}$ (NRC, 2000). A eficiência de utilização da EM para ganho $(\mathrm{kg})$ corresponde ao coeficiente de regressão (inclinação) da equação de regressão da ER em função do CEM (NRC, 2000).

Para estimar a composição corporal de animais dos diferentes grupos genéticos com pesos vivos dentro do intervalo de pesos estudados, foram ajustadas equações de regressão do logaritmo dos conteúdos corporais de proteína, gordura e energia em função do logaritmo do PCVZ, segundo o ARC (1980). Nos casos em que o teste de identidade de modelos (Graybill, 1976) indicou não haver diferenças entre modelos, equações conjuntas foram ajustadas para os dois ou mais grupos genéticos. As equações de predição do conteúdo de proteína, gordura e energia por $\mathrm{kg}$ de ganho de peso foram obtidas por derivação das equações de regressão (ARC, 1980).

\section{Resultados e Discussão}

Utilizando-se a metodologia proposta por Lofgreen \& Garrett (1968) para determinação da ELm, foram ajustadas inicialmente equações de regressão do logaritmo da produção de calor (LogPC) em função do CEM, por unidade de tamanho metabólico $\left(\mathrm{PVJ}^{0,75} \mathrm{ePCVZ}^{0,75}\right)$, específicas para cada um dos três grupos genéticos avaliados. Entretanto, o teste de identidade de modelos (Graybill, 1976) revelou não existirem diferenças $(\mathrm{P}>0,05)$ entre as equações dos diferentes grupos. Assim, foram ajustadas equações comuns para os três grupos genéticos:

$\log \mathrm{PC}=1,9068+0,0014916 \times \operatorname{CEM}\left(\mathrm{PVJ}^{0,75}\right) ; \mathrm{r}^{2}=0,964$ $\log \mathrm{PC}=1,9624+0,0013124 \times \operatorname{CEM}\left(\mathrm{PCVZ}^{0,75}\right) ; \mathrm{r}^{2}=0,918$

Para estimação da ELm, ambas as equações foram extrapoladas para o nível zero de CEM (Lofgreen \& Garrett, 1968). Foram obtidos os valores de $80,7 \mathrm{kcal} / \mathrm{kg}^{0,75} / \mathrm{dia}$ e de $91,7 \mathrm{kcal} / \mathrm{kg}^{0,75} /$ dia para PVJ e PCVZ, respectivamente. Para o valor de ELm, expresso em PVJ, o intervalo de confiança do intercepto $(\beta 0)$ apresentou os limites inferior e superior de 79,6 e $81,7 \mathrm{kcal} / \mathrm{kg}^{0,75} /$ dia, respectivamente.

Empregando-se o modelo não-linear proposto pelo NRC (1981) e estimando-se a ELm sem transformação logarítmica, foram obtidos os valores de $83,6 \mathrm{kcal} / \mathrm{kg}^{0,75} / \mathrm{dia}$ e 93, $0 \mathrm{kcal} / \mathrm{kg}^{0,75} /$ dia para PVJ e PCVZ, respectivamente.

$\mathrm{Na}$ literatura brasileira consultada, não foram encontrados resultados experimentais referentes às exigências de energia líquida de mantença de vacas de corte. Em comparação a animais em crescimento, o valor de ELm encontrado 
neste trabalho foi ligeiramente superior à estimativa de $73 \mathrm{kcal} / \mathrm{kg}^{0,75} /$ dia PVJ, obtida a partir da compilação de diversos trabalhos nacionais (Henrique et al., 2005), uma vez que os intervalos de confiança desta estimativa e deste estudo não se justapõem. Todavia, o valor obtido neste estudo está contido no intervalo de confiança de $77 \pm 6 \mathrm{kcal} /$ $\mathrm{kg}^{0,75} /$ dia PVJ obtido por Lofgreen \& Garrett (1968) e adotado pelo NRC (2000). A partir das equações obtidas neste trabalho, foram estimadas as exigências líquidas diárias de mantença (Tabela 2).

A energia metabolizável de mantença para cada grupo genético foi obtida por regressão da ER em função do CEM, por unidade de tamanho metabólico ( $\mathrm{PVJ}^{0,75}$ e $\mathrm{PCVZ}^{0,75}$ ), específicas para cada um dos três grupos genéticos avaliados. No entanto, o teste de identidade de modelos (Graybill, 1976) revelou não existirem diferenças $(\mathrm{P}>0,05)$ entre as equações dos diferentes grupos. Assim, as equações ajustadas foram comuns para os três grupos genéticos: $\mathrm{ER}=-42,896924+0,390386 \mathrm{CEM}\left(\mathrm{PVJ}{ }^{0,75}\right) ; \mathrm{r}^{2}=0,91$ $\mathrm{ER}=-48,194366+0,387463 \mathrm{CEM}\left(\mathrm{PCVZ}^{0,75}\right) ; \mathrm{r}^{2}=0,91$

Determinando-se o valor de CEM quando a $\mathrm{ER}=0$ (NRC, 2000), estimaram-se os valores de EMm em 109,9 kcal/ $\mathrm{kg}^{0,75} /$ dia PVJ e $124,4 \mathrm{kcal} / \mathrm{kg}^{0,75} / \mathrm{dia}$ PCVZ. Quando se utilizou o modelo não-linear (NRC, 1981), com as restrições propostas por Henrique et al. (2005), os valores de EMm estimados foram de $128,05 \mathrm{kcal} / \mathrm{kg}^{0,75} / \mathrm{dia}$ PVJ e $143,6 \mathrm{kcal} /$ $\mathrm{kg}^{0}, 75 /$ dia PCVZ.

Ferrell \& Jenkins (1984) estimaram a EMm de vacas mestiças adultas (não-gestantes e não-lactantes), oriundas de cruzamentos das raças Angus, Hereford, Jersey, Charolês e Simental. Os menores valores de EMm $\left(129 \mathrm{kcal} / \mathrm{kg}^{0,75} / \mathrm{dia}\right.$ PCVZ) foram observados para as vacas mestiças Angus, enquanto as mestiças Simental apresentaram os maiores valores ( $160 \mathrm{kcal} / \mathrm{kg}^{0,75} / \mathrm{dia}$ PCVZ). Os autores concluíram que animais com maior potencial para produção de leite (mestiços de Jersey e Simental) possuem EMm mais elevada

Tabela 2 - Exigências líquidas diárias de energia para mantença, expressas em Mcal/anim.dia, em função do peso vivo em jejum (PVJ) e do peso de corpo vazio (PCVZ)

Table 2 - Daily requirements for net energy of maintenance, in Mcal/ anim. day, as a function of fast body weight (FBW) and of empty body weight (EBW)

\begin{tabular}{|c|c|c|c|}
\hline $\begin{array}{l}\text { PVJ } \\
F B W \\
\mathrm{~kg}\end{array}$ & $\begin{array}{c}\text { ELm } \\
\text { NEm } \\
\mathrm{Mcal} / \mathrm{d}\end{array}$ & $\begin{array}{c}\text { PCVZ } \\
E B W \\
\mathrm{~kg}\end{array}$ & $\begin{array}{c}\text { ELm } \\
N E m \\
\text { Mcal/d }\end{array}$ \\
\hline 350 & 6,52 & 300 & 6,61 \\
\hline 400 & 7,22 & 350 & 7,42 \\
\hline 450 & 7,88 & 400 & 8,20 \\
\hline 500 & 8,53 & 450 & 8,96 \\
\hline 550 & 9,16 & 500 & 9,70 \\
\hline 600 & 9,78 & 550 & 10,42 \\
\hline
\end{tabular}

em comparação a animais de moderado potencial (mestiços de Angus e Charolês), o que está de acordo com vários outros relatos na literatura (Garret, 1971; Holloway et al., 1975; Lemenager et al., 1980; Taylor et al., 1981).

Solis et al. (1988) em pesquisa com vacas mestiças de raças de corte e leiteiras, concluíram que as mestiças de corte são menos exigentes em EMm que aquelas de alto potencial leiteiro. Os autores relataram que vacas mestiças Holandês $\times$ Jersey, Angus $\times$ Jersey e Hereford $\times$ Holandês apresentaram EMm $17 \%$ maior que em vacas mestiças Brahman $\times$ Hereford e Angus $\times$ Hereford. Além disso, vacas puras das raças de corte, Angus, Hereford e Brahman, tomadas em conjunto, tiveram valor médio de EMm $27 \%$ menor que os animais das raças de aptidão leiteira (Jersey e Holandês). Neste sentido, o NRC (2000) estabeleceu que vacas de raças leiteiras exigem $20 \%$ mais energia para mantença que as raças de corte e que as mestiças exigem valores intermediários.

Neste estudo, as maiores exigências de vacas de raças com potencial leiteiro elevado como Holandês, Jersey e Simental foram atribuídas por Smith \& Baldwin (1973), Ferrell et al. (1976) e Solis et al. (1988) ao maior tamanho de seus órgãos internos em relação às raças de corte, como a Hereford, Angus e Brahman.

O fato de a EMm não ter diferido entre os animais dos três grupos genéticos avaliados neste trabalho pode ser em parte explicado pelo uso de animais mestiços de raças de moderado potencial leiteiro. Provavelmente, nem mesmo as vacas F1 Pardo-Suíço-Nelore teriam potencial leiteiro elevado, pois foram utilizados reprodutores Pardo-Suíço de linhagem de corte.

Segundo o NRC (2000), a exigência de mantença dos animais zebuínos é $10 \%$ menor que a dos animais taurinos, em razão do menor potencial genético para produção, uma conseqüência da adaptação das raças zebuínas a condições ambientais menos favoráveis (NRC, 2000). No entanto, Ferrell \& Jenkins (1998), em pesquisa com novilhos das subespécies Bos indicus (Boran, Brahman e Tuli) e Bos taurus (Angus e Herford), não observaram diferenças entre as exigências de mantença das raças zebuínas e taurinas. Do mesmo modo, Solis et al. (1988) não encontraram diferença na EMm de vacas Angus e Brahman. Neste trabalho, não houve diferença nas exigências de EMm de vacas Nelore e F1 Angus-Nelore.

Os valores de EMm obtidos neste trabalho encontram-se na faixa de variação encontrada na literatura para vacas de corte de diversas raças: $178 \mathrm{kcal} / \mathrm{kg}^{0,75} / \mathrm{dia}$ PCVZ para vacas Hereford (Neville \& McCullough, 1969); 137 kcal/kg0,75/dia PCVZ, para vacas Charolês e Hereford (Klosterman et al., 1968) e 99,3 kcal $/ \mathrm{kg}^{0,75} /$ dia PCVZ para vacas zebuínas e seus mestiços (Solis et al., 1988). 
A exigência de energia de mantença, quando expressa em energia metabolizável (EMm), está sujeita a variações referentes às diferenças na eficiência com que a EM é utilizada para mantença $(\mathrm{Km})$. Esta eficiência, em grande parte, é influenciada pela concentração de EM da ração. A partir da compilação de resultados de diversos experimentos utilizando a técnica do abate comparativo, o NRC (1981) concluiu que o decréscimo da concentração de EM dos alimentos de 3,2 para 2,1 Mcal $/ \mathrm{kg}$ de MS reduziu o $\mathrm{km} \mathrm{de} 70 \%$ para $58 \%$ e o kg de 50 a $25 \%$, respectivamente. Desse modo, diferenças na composição das rações experimentais utilizadas podem justificar parte da amplitude dos valores de EMm encontrados na literatura.

Neste trabalho, a eficiência de utilização da EM para mantença $(\mathrm{Km})$ foi determinada de acordo com o NRC (2000), como o quociente da ELm pela EMm $(\mathrm{Km}=\mathrm{ELm} /$ $\mathrm{EMm})$. Foi encontrado neste estudo $\mathrm{Km}=0,73$. A eficiência de utilização da EM para ganho $(\mathrm{Kg})$ também foi calculada segundo o NRC (2000) e correspondeu ao coeficiente de regressão $(\beta 0)$ da equação de regressão da ER em função do CEM: $\mathrm{Kg}=0,39$. Os valores de $\mathrm{Km}$ e $\mathrm{Kg}$ calculados foram comuns para os três grupos genéticos e para o PVJ e o PCVZ.
Solis et al. (1988) não encontraram diferença na eficiência de utilização da EM para mantença entre vacas da raça Brahman e Angus, o que está de acordo com resultados descritos por Ferrell \& Jenkins (1998), que também não encontraram diferenças na eficiência de utilização da EM entre novilhas das mesmas raças.

Esses resultados confirmam a ausência de diferença na eficiência de EM entre vacas F1 Red Angus-Nelore e vacas Nelore. Tedeschi et al. (2002) observaram valores de eficiência de utilização da EM para mantença de 70\% (Km) para novilhas Nelore e de $64 \%$ para touros da mesma raça submetidos a tratamentos diferentes.

Véras et al. (2001) obtiveram valores de Kg para novilhos Nelore de 0,44 ao utilizarem ração com 2,35 Mcal $/ \mathrm{kg}$ na MS, valor $11 \%$ superior ao encontrado neste trabalho. Esses autores verificaram variação no $\mathrm{Kg}$ de cinco rações, com 2,11 a 2,52 Mcal de EM/kg de MS de 0,32 a 0,69, respectivamente.

Para estudar as mudanças na composição corporal dos animais, com o aumento do peso vivo, foram ajustadas as equações de regressão do logaritmo do conteúdo corporal de proteína e gordura, em kg, em função do logaritmo do peso de corpo vazio (ARC, 1980), para os três grupos genéticos.

Tabela 3 - Parâmetros da regressão do logaritmo dos conteúdos de proteína $(\mathrm{kg})$, gordura (kg) e energia (mcal) para vacas mestiças e Nelore, em função do logaritmo do peso de corpo vazio (PCVZ), em kg, e equações de predição do ganho de proteína e gordura, em kg por kg de ganho de peso de corpo vazio (GPCVZ), em função do PCVZ

Table 3 - Parameters of regression of logarithm of body contents of protein $(\mathrm{kg})$, fat $(\mathrm{kg})$ and energy (Mcal) for crossbred and Nellore cows, as a function of logarithm empty body weight (EBW), in $\mathrm{kg}$, and prediction equations for protein and fat gain, in $\mathrm{kg}$, and for energy gain, in Mcal, per kg of EBW gain as a function of the EBW

Componente

Component
Parâmetros das regressões conteúdos corporais de proteína, gordura e energia Parameters of regression equations of body content of protein, fat and energy $\beta$ $\mathrm{r}^{2}$

Intercepto

Intercept

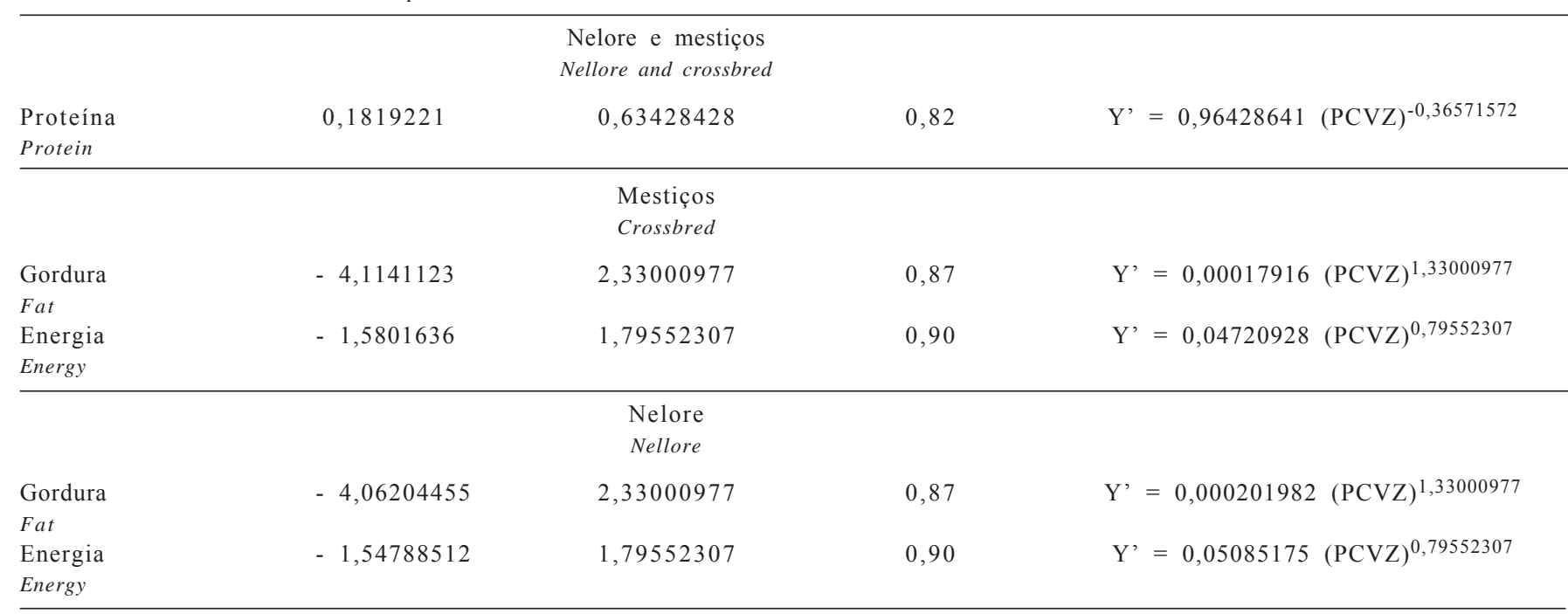

Equação de predição do acréscimo de proteína, gordura e energia por $\mathrm{kg}$ de ganho Prediction equations for gains of protein, fat and energy per $\mathrm{kg}$ of weight gain 
Entretanto, o teste de identidade de modelos (Graybill, 1976) revelou não existir diferença $(\mathrm{P}>0,05)$ entre as equações dos três grupos, no que se refere ao aumento de proteína corporal com a elevação do peso de corpo vazio. Desta forma, chegou-se a uma equação única para proteína para os três grupos genéticos. Para energia, o teste de identidade de modelos revelou não existir diferença entre as equações dos dois grupos mestiços, as quais diferiram $(\mathrm{P}<0,05)$ daquela ajustada para o Nelore, enquanto para gordura verificou-se diferença entre interceptos para mestiços e Nelore. Foram, portanto, ajustadas equações específicas para o Nelore e equações comuns para os dois grupos mestiços. Por derivação das respectivas equações de regressão ajustadas
(Tabela 3), foram obtidas equações de predição do ganho de proteína, gordura e energia, por $\mathrm{kg}$ de ganho de peso de corpo vazio (GPCVZ), para as vacas dos três grupos genéticos, com o aumento do peso de corpo vazio.

Com base nas equações apresentadas na Tabela 3, foram estimados os conteúdos corporais de proteína e gordura, em kg, e de energia, em Mcal, e as concentrações de proteína, gordura e energia por kg de PVJ e PCVZ (Tabelas 4 e 5).

Os conteúdos totais de proteína, gordura e energia aumentaram à medida que o peso corporal das vacas se elevou. Por outro lado, com o aumento do peso corporal, as concentrações corporais de proteína diminuíram e as de

Tabela 4 - Peso de corpo vazio (PCVZ), peso vivo em jejum (PVJ), conteúdos corporais totais de proteína (PT), em kg, concentrações de proteína no corpo vazio (CP) e por kg de ganho (CPG) dos animais dos três grupos genéticos, em função do PCVZ

Table 4 - Empty body weight (EBW), fast body weight (FBW), total body contents of protein (TP), in kg, concentrations of protein in EBW (PC) and in weight gain $(P G)$, in animals from the three genetic groups, as a function of the EBW

\begin{tabular}{|c|c|c|c|c|c|}
\hline \multicolumn{3}{|c|}{$\begin{array}{l}\text { Peso corporal } \\
\text { Body weight }\end{array}$} & \multicolumn{2}{|c|}{$\begin{array}{c}\text { Conteúdo corporal total e por } \mathrm{kg} \\
\text { Total body contents and per } \mathrm{kg}\end{array}$} & \multirow{2}{*}{$\begin{array}{c}\text { Composição do ganho } \\
\text { Composition of gain }\end{array}$} \\
\hline \multirow{3}{*}{$\begin{array}{l}\text { PCVZ (kg) } \\
E B W\end{array}$} & \multicolumn{2}{|c|}{$\begin{array}{l}\mathrm{PVJ}(\mathrm{kg}) \\
\quad F B W\end{array}$} & \multirow{3}{*}{$\begin{array}{l}\mathrm{P} \mathrm{T} \\
T P \\
\mathrm{~kg}\end{array}$} & \multirow{3}{*}{$\begin{array}{c}C P \\
P C \\
\mathrm{~g} / \mathrm{kg} \mathrm{PCVZ} \\
g / \mathrm{kg} E B W\end{array}$} & \\
\hline & Nelore & Mestiços & & & $\mathrm{g} / \mathrm{kg}$ ganho de PCVZ \\
\hline & Nellore & Crossbred & & & $\mathrm{g} / \mathrm{kg}$ of $E B W$ gain \\
\hline 400 & 470 & 478 & 67,9 & 170 & 108 \\
\hline 450 & 527 & 541 & 73,3 & 163 & 103 \\
\hline 500 & 583 & 603 & 78,3 & 157 & 99 \\
\hline 550 & 640 & 666 & 83,2 & 151 & 96 \\
\hline
\end{tabular}

Tabela 5 - Peso de corpo vazio (PCVZ), peso vivo em jejum (PVJ), conteúdos corporais totais de gordura e energia, em kg e mcal, concentração de gordura ( $/ \mathrm{kg}$ ) e energia (mcal/ $\mathrm{kg}$ ), no PCVZ e conteúdo no ganho de gordura (g/kg) e energia (mcal/kg) de vacas Nelore e mestiças, em função do PCVZ

Table 5 - Empty body weight (EBW), fast body weight (FBW), total body contents of fat ( $\mathrm{kg}$ ) and energy (Mcal), concentrations of fat ( $\mathrm{g} / \mathrm{kg}$ ) and energy (Mcal/ $/ \mathrm{kg})$, in EBW and content in weight gain of fat $(\mathrm{g} / \mathrm{kg})$ and energy (Mcal $/ \mathrm{kg})$ for Nellore and crossbred cows, as function of EBW

\begin{tabular}{|c|c|c|c|c|c|c|c|}
\hline \multicolumn{2}{|c|}{$\begin{array}{l}\text { Peso corporal } \\
\text { Body weight }\end{array}$} & \multicolumn{2}{|c|}{$\begin{array}{c}\text { Conteúdo corporal total } \\
\text { Total body content }\end{array}$} & \multicolumn{2}{|c|}{$\begin{array}{l}\text { Concentração no PCVZ } \\
\text { Concentration in } E B W\end{array}$} & \multicolumn{2}{|c|}{$\begin{array}{c}\text { Conteúdo no ganho } \\
\text { Concentration in weight gain }\end{array}$} \\
\hline & & \multirow{2}{*}{$\begin{array}{c}\text { Gordura } \\
\text { Fat } \\
\text { kg }\end{array}$} & \multirow{2}{*}{$\begin{array}{c}\text { Energia } \\
\text { Energy } \\
\text { Mcal }\end{array}$} & \multirow{2}{*}{$\begin{array}{c}\text { Gordura } \\
\text { Fat } \\
\mathrm{g} / \mathrm{kg}\end{array}$} & \multirow{2}{*}{$\begin{array}{c}\text { Energia } \\
\text { Energy } \\
\text { Mcal/kg }\end{array}$} & \multirow{2}{*}{$\begin{array}{c}\text { Gordura } \\
\text { Fat } \\
\mathrm{g} / \mathrm{kg}\end{array}$} & \multirow{2}{*}{$\begin{array}{c}\text { Energia } \\
\text { Energy } \\
\text { Mcal/kg }\end{array}$} \\
\hline & & & & & & & \\
\hline PCVZ (kg) & PVJ (kg) & & & - _ & ore- & & - - \\
\hline$E B W$ & FBW Nellore & & & & & & \\
\hline 300 & 356 & 51,24 & 794 & 171 & 2,65 & 398 & 4,75 \\
\hline 350 & 413 & 73,39 & 1047 & 210 & 2,99 & 489 & 5,37 \\
\hline 400 & 470 & 100,18 & 1331 & 250 & 3,33 & 584 & 5,97 \\
\hline 450 & 527 & 131,82 & 1644 & 293 & 3,65 & 683 & 6,56 \\
\hline 500 & 583 & 168,49 & 1987 & 337 & 3,97 & 785 & 7,14 \\
\hline PCVZ (kg) & PVJ (kg) & & & - & stiças- & & - \\
\hline$E B W$ & $F B W$ & & & Crossbred & & & \\
\hline 300 & 354 & 45,46 & 737 & 152 & 2,46 & 353 & 4,41 \\
\hline 350 & 416 & 65,10 & 972 & 186 & 2,78 & 433 & 4,99 \\
\hline 400 & 478 & 88,86 & 1236 & 222 & 3,09 & 518 & 5,55 \\
\hline 450 & 541 & 116,92 & 1527 & 260 & 3,39 & 605 & 6,09 \\
\hline 500 & 603 & 149,46 & 1845 & 299 & 3,69 & 696 & 6,62 \\
\hline 550 & 666 & 186,62 & 2189 & 339 & 3,98 & 791 & 7,15 \\
\hline
\end{tabular}


gordura e energia aumentaram, quando expressas em função do PCVZ. Estes resultados estão de acordo com as informações de Berg \& Buterfield (1976), ARC (1980) e Owens et al. (1993). Concordam também com resultados referentes a bovinos machos castrados e intactos de raças zebuínas e mestiças europeu-zebu (Reid \& Rob, 1971; Gonçalves, 1988; Lana et al. 1992; Fontes, 1995; Jorge et al., 1999).

O ganho de proteína por kg de tecido ganho decresceu à medida que o peso vivo se elevou, paralelamente ao aumento verificado nas concentrações de gordura, indicando a desaceleração do crescimento muscular e desenvolvimento mais rápido do tecido adiposo, concomitantemente com o aumento do peso corporal, o que está de acordo com o descrito por Berg \& Butterfield (1976) e Owens et al. (1993). A redução no ganho de proteína, entretanto, ocorreu em ritmo mais lento do que se poderia esperar, uma vez que se trabalhou com vacas adultas que, pressupostamente, teriam menor impulso para crescimento muscular.

De acordo com Owens et al. (1995), em bovinos em crescimento, o ganho de proteína declina a zero quando os animais atingem seu peso à maturidade, o que ocorreria quando a porcentagem de gordura no corpo vazio atinge, aproximadamente, $36 \%$. Neste trabalho, as vacas Nelore e mestiças abatidas com PCVZ mais elevados $(500$ e $550 \mathrm{~kg}$, respectivamente) teriam teores de gordura corporal de 33,7 e 33,9\%, próximos de 36\%. Entretanto, apresentavam ganhos de proteína ainda relativamente elevados ( 99 a $96 \mathrm{~g}$ por dia, respectivamente). Esses resultados evidenciam que vacas Nelore e mestiças adultas com escore inicial 4, em uma escala de 1 a 9 , proveniente de pastagens, ao receberem ração balanceada são capazes de expressar ganho de peso vivo elevado (173 $\mathrm{kg}$ em um período de 120 dias, no caso das F1 Red Angus-Nelore) e que parte considerável do ganho é representado por massas musculares, traduzindo-se em ganho diário de proteína, ainda, alto. Esses animais, ao serem mantidos em regime de pasto tropical sem suplementação recebendo nível de energia relativamente baixo, atingem pesos corporais de equilíbrio, conforme descrito por Williams \& Jenkins (2003), abaixo do peso à maturidade potencial da raça, o que as capacita a ganhos de peso elevados ao receberem rações mais ricas em energia.

Solis et al. (1988) observaram em vacas mestiças Europeu-Zebu de $450 \mathrm{~kg}$ de PCVZ conteúdo corporal total médio de proteína de 76,6 kg. Nas vacas mestiças de raças de corte, o valor foi de $79 \mathrm{~kg}$ e, nas mestiças de raças leiteiras $72,5 \mathrm{~kg}$, para o mesmo PCVZ. Quando esses autores consideraram em conjunto todas as vacas mestiças e animais puros das raças utilizadas nos cruzamentos, o conteúdo médio encontrado foi de $75,3 \mathrm{~kg}$ de proteína em $450 \mathrm{~kg}$ de PCVZ, valor praticamente igual ao observado neste trabalho para o mesmo PCVZ. O conteúdo de gordura corporal encontrado por esses autores para mestiças obtidas do cruzamento com touros de várias raças com fêmeas Hereford foi de 109,4 kg, 5\% menor que o encontrado quando os autores utilizaram as mesmas raças paternas (taurinas) com vacas da raça Brahman $(115,0 \mathrm{~kg})$. Esses resultados mostram a mesma tendência verificada neste trabalho, em que o conteúdo de gordura corporal de vacas Nelore foi maior que o de vacas mestiças Europeu-Zebu (F1 Pardo-Suíço-Nelore e F1 Red Angus-Nelore). O valor médio do conteúdo de gordura corporal verificado neste trabalho para animais de $450 \mathrm{~kg}$ de PCVZ foi $10 \%$ superior aos descritos por esses autores.

\section{Conclusões}

Não foi evidenciada diferença nas exigências de energia líquida e metabolizável para mantença entre vacas adultas Nelore e suas mestiças F1 Red Angus e Pardo-Suíço. A um mesmo peso corporal, vacas Nelore e suas mestiças F1 Red Angus e Pardo-Suíço não diferem quanto às proporções de proteína corporal e ganho, no entanto, as vacas Nelore acumulam mais gordura e energia.

\section{Literatura Citada}

AGRICULTURAL RESEARCH COUNCIL - ARC. The nutrient requirements of ruminants. London: 1980. $351 \mathrm{p}$.

BERG, R.T.; BUTTERFIELD, R.M. New concepts of cattle growth. New York: Sidney University, 1976. 240p.

BERNDT, A.; HENRIQUE, W.; LEME, P.R. et al. Exigências líquidas de proteína e energia para crescimento de tourinhos Santa Gertrudis em dietas de alto teor de concentrado. Revista Brasileira de Zootecnia, v.31, n.5, p.2098-2104, 2004

BOIN, C. Alguns dados sobre exigências de energia e de proteínas de zebuínos. In: SIMPÓSIO INTERNACIONAL SOBRE EXIGÊNCIAS NUTRICIONAIS DE RUMINANTES, 1995, Viçosa, MG. Anais... Viçosa, MG: Universidade Federal de Viçosa, 1995. p.457-465.

FERREL, C.L.; JENKINS, T.G. Energy utilization by Hereford and Simmental males and females. Animal Production, v.41, p.5361,1985 .

FERRELL, C.L.; JENKINS, T.G. Body composition and energy utilization by steers of diverse genotypes fed a high-concentrate diet during the finishing period: II. Angus, Boran, Brahman, Hereford, and Tuli sires. Journal of Animal Science, v.76, n.2, p.647-657, 1998.

FERRELL, C.L.; GARRETT, W.N.; HINMAN, N. et al. Energy utilization by pregnant heifers. Journal of Animal Science, v.42, n.4, p.937-950, 1976.

FERRELL, C.L.; JENKINS, T.G. Energy utilization by mature, nonpregnant, nonlactating cows of different types. Journal of Animal Science, v.58, n.1, p.234-243, 1984.

FONTES, C.A.A.; OLIVEIRA, R.C.; ERBESDOBLER, E.D. et al Uso do abate comparativo na determinação da exigência de energia de mantença de gado de corte pastejando capim-elefante: 
descrição da metodologia e dos resultados. Revista Brasileira de Zootecnia, v.34, n.5, p.1721-1729, 2005.

FONTES, C.A.A. Composição corporal, exigências líquidas de nutrientes para ganho de peso e desempenho produtivo de animais zebuínos e mestiços europeu-zebu. Resultados experimentais. In: SIMPÓSIO INTERNACIONAL SOBRE EXIGÊNCIAS NUTRICIONAIS DE RUMINANTES, 1995, Viçosa, MG. Anais...Viçosa, MG: Universidade Federal de Viçosa, 1995. p.419-455.

GARRETT, W.N. Energetic efficiency of beef and dairy steers. Journal of Animal Science, v.32, n.3, p.451-460, 1971.

GOERING, H.K.; van SOEST, P.J. Forage fiber analysis (apparatus, reagents, procedures and some applications). Washington: United States Department of Agriculture, 1970. 20p. (Agriculture Handbook, 379).

GONÇALVES, L.C. Digestibilidade, composição corporal, exigências nutricionais e características de carcaças de zebuínos, taurinos e bubalinos. Viçosa, MG: Universidade Federal de Viçosa, 1988. 238p. Tese (Doutorado em Zootecnia) - Universidade Federal de Viçosa, 1988.

GRAYBILL, F.A. Theory and application of the linear model. Massachusetts: Duxburg Press, 1976. 704p.

HENRIQUE, D.S.; VIEIRA, R.A.M.; MALAFAIA, P.A.M. et al. Estimation of the total efficiency of metabolizable energy utilization for maintenance and growth by cattle in tropical conditions. Revista Brasileira de Zootecnia, v.34, n.3, p.1006-1016, 2005.

HOLlOWAY, J.W.; STEPHENS, D.F.; WHITEMAN, J.V. Performance of 3-years old Hereford, Hereford-Holstein and Holstein cows on range and in dry lot. Journal of Animal Science, v.40, p.114-122, 1975.

JORGE, A.M.; FONTES, C.A.A.; PAULINO, M.F. Composição corporal de bovinos de quatro raças zebuínas, abatidos em diferentes estádios de maturidade. Revista Brasileira de Zootecnia, v.28, n.2, p.388-394, 1999.

KLOSTERMAN, E.W.; SANFORD, L.G.; PARKER, C.F. Effect of cow size and condition and ration protein content upon maintenance requirements of mature beef cows. Journal of Animal Science, v.27, n.1, p.242-246, 1968.

LANA, R.P.; FONTES, C.A.A.; PERON, A.J. et al. Composição corporal e exigências de energia, proteína e macroelementos minerais $(\mathrm{Ca}, \mathrm{P}, \mathrm{Mg}, \mathrm{Na}$ e $\mathrm{K})$ de novilhos de cinco grupos raciais em confinamento. 1. Conteúdo corporal e do ganho de peso em gordura, proteína e energia. Revista Brasileira de Zootecnia, v.21, n.3, p.518-527, 1992.

LEMENAGER, R.P.; NELSON, L.A.; HENDRIX, K.S. Influence of cow size and breed type on energy requirements. Journal of Animal Science, v.1, n.3, p.566-576, 1980.

LIPPKE, H.; ELLIS, W.C.; JACOBS, B.F. Recovery of indigestible fiber from feces of sheep and cattle on forage diets. Journal of Dairy Science, v.69, n.2, p.403-412, 1986.

LOFGREEN, G.P.; GARRETT, W.N. A system for expressing net energy requeriments and feed values for growing and finishing beef cattle. Journal of Animal Science, v.27, n.3, p.793$806,1968$.

LONG, C.R. Crossbreeding for beef production: experimental results. Journal of Animal Science, v.51, n.5, p.1197-1223, 1980.
NATIONAL RESEARCH COUNCIL - NRC. Nutrient requirements of beef cattle. 8.ed. Washington, D.C.: 2000. 234p.

NATIONAL RESEARCH COUNCIL - NRC. Nutritional energetics of domestic animals \& Glossary of energy terms. 2.ed. Washington, D.C.: National Academy Press, 1981. 54p.

NEVILLE, W.E.; McCUlLOUGH, M.E. Calculated energy requirements of lacting and non-lacting cows. Journal of Dairy Science, v.11, p.565-572, 1969.

NOCEK, E.J. In situ and other methods to estimate ruminal protein and energy digestibility: a review. Journal of Dairy Science, v.71, n.8, p.2051-2069, 1988.

OWENS, F.N.; DUBESKI, P.; HANSON, C.F. Factors that the growth and development of ruminants. Journal of Animal Science, v.71, n.11, p.3138-3150, 1993.

OWENS, F.N.; GILL, D.R.; SECRIST, D.S. et al. Review of aspects of growth and development of feedlot cattle. Journal of Animal Science, v.73, n.10, p.3152-3172, 1995.

PAULINO, P.V.R.; COSTA, M.A.L.; VALADARES FILHO, S.C. et al. Exigências nutricionais de zebuínos. Energia. Revista Brasileira de Zootecnia, v.33, n.3, p.781-791, 2004.

REID, J.T.; ROBB, J. Relationship of body composition to energy intake and energy efficiency. Journal of Dairy Science, v.54, n.4, p.553-564, 1971.

SILVA, D.J.; QUEIROZ, A.C. Análise de alimentos: métodos químicos e biológicos. 3.ed. Viçosa, MG: Editora UFV, 2002. $235 \mathrm{p}$.

SMITH, N.E.; BALDWIN, R.L. Effects of breed, pregnancy and lactation on weight of organs and tissues in dairy cattle. Journal of Animal Science, v.57, n.9, p.1055-1060, 1973.

SOLIS, J.C.; BYERS, F.M.; SCHELLING, G.T. et al. Maintenance requirements and energetic efficiency of cows of different breed types. Journal of Animal Science, v.66, n.3, p.764-773, 1988.

TAYLOR, C.S.; YOUNG, G.B. Equilibrium weight in relation to food intake and genotype in twin cattle. Animal Production, v. 10, n.3, p.393-412, 1968

TAYLOR, C.S.; TURNER, H.G.; YOUNG, G.B. Genetic control of equilibrium maintenance efficiency in cattle. Animal Production, v.33, p.179-194, 1981.

TEDESCHI, L.O.; BOIN, C.; FOX, D.G. et al. Energy requirement for maintenance and growth of Nellore bulls and steers fed high-forage diets. Journal of Animal Science, v.80, n.6, p.1671-1682, 2002.

VÉRAS, A.S.C.; VALADARES FILHO, S.C.; SILVA, J.F.C. et al. Eficiência de utilização da energia metabolizável para mantença e ganho de peso e exigências de energia metabolizável e de nutrientes digestíveis totais de bovinos nelore, não-castrados. Revista Brasileira de Zootecnia, v.30, n.3, p.904-910, 2001

WILLIAMS, C.B.; JENKINS; T.G. A dynamic model of metabolizable energy utilization in growing and mature cattle. I. Metabolizable energy of maintenance and support metabolism. Journal of Animal Science, v.81, n.6, p.1371$1381,2003$.
Recebido: 1/12/2006 Aprovado: 9/7/2007 